\title{
Evaluation of Laccase Production by Two White-rot Fungi Using Solid-state Fermentation with Different Agricultural and Forestry Residues
}

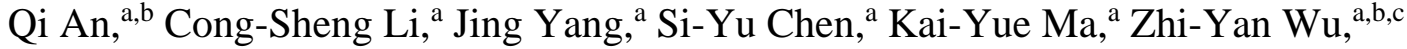 \\ Lu-Sen Bian, ${ }^{\mathrm{d}}$ and Mei-Ling Han ${ }^{\mathrm{a}, \mathrm{b}, \mathrm{c}, *}$
}

\begin{abstract}
Pleurotus ostreatus and a newly isolated Ganoderma lingzhi strain were evaluated for their laccase secretion capacity by solid-state fermentation with different agricultural and forestry residues. There was a significant difference among fungi for biosynthetic potential. In principle, the laccase secretion capacity of $P$. ostreatus $C Y 568$ was stronger than that from $G$. lingzhi Han 500. Different species of fungi had a preference for agricultural and forestry residues. The presence of cottonseed hull and Populus beijingensis were helpful for accelerating the rate of laccase enzyme production of $P$. ostreatus CY 568. Cottonseed hull and corncob were useful for improving the production of laccase from G. lingzhi Han 500. Continuous and stable laccase production was found on cottonseed hull by $P$. ostreatus CY 568 and $G$. lingzhi Han 500 . Maximum laccase activity obtained from $P$. ostreatus CY 568 on Toona sinensis, Sophora japonica, Salix babylonica, Populus beijingensis, corncob, cottonseed hull, and straw of Oryza sativa was higher than that from G. lingzhi Han 500, and was nearly 1.16-fold, 1.59-fold, 3.32-fold, 1.39-fold, 1.08-fold, 1.08-fold, and 1.36-fold, respectively. These findings will be helpful for developing new productive strains and expanding more species for industrial application to obtain efficient and low-cost laccase.
\end{abstract}

Keywords: Pleurotus ostreatus; Ganoderma lingzhi; Laccase production; Agricultural and forest residues; Solid-state fermentation

Contact information: a: College of Life Science, Langfang Normal University, Langfang 065000, Hebei, China; b: Technical Innovation Center for Utilization of Edible and Medicinal Fungi in Hebei Province, Langfang 065000, Hebei, China; c: Edible and Medicinal Fungi Research and Development Center of Universities/Colleges in Hebei Province, Langfang 065000, Hebei, China; d: Experimental Centre of Forestry in North China, Chinese Academy of Forestry, Beijing 102300, China;

*Corresponding author: meilinghan309@163.com

\section{INTRODUCTION}

White-rot fungi (WRF) are important eukaryotic microorganisms that grow on dead and fallen trees and degrade lignocellulose (Ko et al. 2001). Lignin degradation plays an important role in the carbon cycle and/or refractory degradation in nature. Formation of the fungi fruit body is also a process of producing lignocellulolytic enzymes using agricultural and forestry residues. Scientists have studied white-rot fungi for its ability to produce extracellular lignocellulotic enzymes, including ligninolytic enzymes that degrade lignin and hydrolytic enzymes that degrade cellulose and hemicellulose (An et al. 2016a,b; Han et al. 2020b; Lira-Perez et al. 2020). Ligninolytic enzymes of WRF mainly include oxidase (e.g., laccase) and peroxidases (e.g., lignin peroxidase, manganese peroxidase [versatile peroxidase]). Hydrolytic enzymes are comprised of cellulase and hemicellulase 
corresponding to the role of degrading cellulose and hemicellulose. In addition, some genera of white-rot basidiomycetes, e.g., Trametes and Pleurotus, are an efficient producer of extracellular enzymes, such as laccases (EC 1.10.3.2) (Castanera et al. 2015; An et al. 2018, 2020a,b; Wang et al. 2018; Singh et al. 2019).

Laccases are distributed among plants, fungi, bacteria, and some insects (Shrestha et al. 2016). Laccase is a multi-copper oxidase that catalyzes the oxidation of various phenolic and non-phenolic substrates related to lignin structure, while reducing oxygen to water (Sharma et al. 2019). Laccase exhibits a wide and extraordinary range of natural substrates. For this reason, it is used in industrial and biotechnology applications in several areas, such as improving fiber properties, degradation of antibiotics and other pharmaceutical products, fuels, detoxification of environmental pollutants, stabilization lignin by providing precursors to chemicals, and pulp bleaching in the paper industry (Bertrand et al. 2017; Mate and Alcalde 2017; Agrawal et al. 2018; Su et al. 2018; Bilal et al. 2019; Singh and Arya 2019; Zerva et al. 2019). In addition, it is also used in healthcare products, nanobiotechnology, the pharmaceutical industry (Fperrer-Miralles et al. 2009). In addition, it is used in the removal of phenolic compounds in wine and as a biosensor $(\mathrm{Ba}$ and Kumar 2017; Yang et al. 2017; Becker and Wittmann 2019; Unuofin et al. 2019; Zerva et al. 2019).

A wide range of applications in biotechnological, industrial, and environmental protection require large amounts of enzymes. Unfortunately, laccases secreted by wild or cultivated fungi in simple fermentation conditions are not suitable for commercial purposes due to the disadvantages of low yields, weak activity, and low economic efficiency (Mate and Alcalde 2017; Rodrigues et al. 2019; An et al. 2020a). Developing new productive strains and selecting low-cost lignocellulosic materials for fermentation are helpful for opening new commercial and industrial opportunities for their uses in economic development and environmental protection (Janusz et al. 2015; Huang et al. 2019; An et al. 2020b).

Currently, enzymes are mainly produced by conventional fermentation methods (Christopher et al. 2005). However, in recent years, more attention has been paid to the production of enzymes by solid-state fermentation (SSF), utilizing agro-industrial residues (Singhania et al. 2009; Sharma et al. 2019). The advantages of conventional submerged fermentation are that it is convenient to control fermentation conditions and suitable for large-scale fermentation in industry. However, the main advantages of solid-state fermentation, compared to submerged fermentation, have been higher product yield and higher cost-effectiveness, as well as ease in controlling conditions and using the method (e.g., less spraying and vibration) (Szendefy et al. 2006; Osma et al. 2011; Sharma et al. 2019). Furthermore, solid-state fermentation, which uses cultivated types of fungi to produce enzymes, is particularly beneficial because it mimics the fungi natural habitat, thus providing higher enzyme yields (Steudler and Bley 2015). In recent years, the SSF method has emerged as an attractive strategy for producing lignocellulolytic enzymes (Soccol et al. 2017). The application of enzymes obtained from SSF will make the enzymatic production process less cumbersome to reduce the overall cost and improve its feasibility and economic viability on a commercial scale (Sharma et al. 2019). Meanwhile, lignocellulosic biomass is the most commonly used material for solid-state fermentation. Lignocellulosic biomass, mainly including agro-industrial residues (e.g., straw, corncob, and hazelnut husk) and forest residue (e.g., leaves, branches), are principally made up of three major components: cellulose, hemicellulose, and lignin (Sitarz et al. 2013; Han et al. 2020b). The types and quantities of agricultural and forestry wastes, such as cottonseed hull, corn straw, 
and leaves, and wheat straw are huge in China. Rational utilization of these lignocellulosic residues will become an important aspect to solve environmental problems. The use of various types of lignocellulosic residues to produce enzymes is convenient, efficient, environmentally friendly, and economical (Lamia et al. 2017).

Laccase production by fungi can be affected by a variety of factors, including kinds of lignocellulosic residues, $\mathrm{pH}$, metal ions, temperature, and aromatic compounds (Metreveli et al. 2017; Filipe et al. 2019; An et al. 2020a,b; Rajavat et al. 2020). Moreover, type of fungal species or strains is an important factor affecting laccase production. Laccase activity of different strains from the genera, Pleurotus and Flammulina on substrate of wood, tree leaves, corncob, and wheat straw have been investigated (An et al. 2020b; Han et al. 2017, 2020b). Laccase production of Ganoderma lucidum has been discussed in the effect of rice and sunflower agro-residues, phenolic, and metallic inducers (Kuhar and Papinutti 2014; You et al. 2014; Postemsky et al. 2017; Palazzolo et al. 2019). However, comparative study of strain belonging to genera, Ganoderma and Pleurotus has not been reported. Furthermore, laccase production of genus Ganoderma and Pleurotus cultured by numerous agricultural and forestry residues, e.g. straw of Oryza sativa, Salix babylonica, and Sophora japonica, has not been reported. However, in order to reduce the production cost of laccase, it is very necessary to screen low-cost lignocellulosic materials suitable for laccase production by fungi. In this context, the objective of the present work was to evaluate the presence of different agricultural and forestry residues on the production of laccase by $P$. ostreatus and one newly isolated white-rot fungus Ganoderma sp. on solidstate fermentation. The aim was to select suitable agricultural and forestry residues to provide a basis for: 1.) developing new productive strains and 2.) expanding more species for industrial application to obtain efficient and low-cost laccase.

\section{EXPERIMENTAL}

\section{Materials}

Fungi

The microorganisms used in this study were Pleurotus ostreatus CY 568 and Ganoderma sp. Han 500. Pure cultures of P. ostreatus CY 568 preserved at $4{ }^{\circ} \mathrm{C}$ were kindly provided by the Institute of Microbiology, Beijing Forestry University (Beijing, China). Another selected strain, Ganoderma sp. Han 500 was collected from Mount Tai Scenic Spot in Taian city, Shandong Province, China. The strain was isolated and purified on Complete Yeast Medium (CYM) (glucose $20 \mathrm{~g} / \mathrm{L}$, peptone $2 \mathrm{~g} / \mathrm{L}$, yeast extract $2 \mathrm{~g} / \mathrm{L}$, $\mathrm{MgSO}_{4} \cdot 7 \mathrm{H}_{2} \mathrm{O} 0.5 \mathrm{~g} / \mathrm{L}, \mathrm{K}_{2} \mathrm{HPO}_{4} \cdot 3 \mathrm{H}_{2} \mathrm{O} 1 \mathrm{~g} / \mathrm{L}, \mathrm{KH}_{2} \mathrm{PO}_{4} 0.46 \mathrm{~g} / \mathrm{L}$, and agar $\left.15 \mathrm{~g} / \mathrm{L}\right)$. They were maintained by subculturing them in Malt Extract Agar (MEA) medium (glucose 10 $\mathrm{g} / \mathrm{L}$, malt extract $20 \mathrm{~g} / \mathrm{L}, \mathrm{KH}_{2} \mathrm{PO}_{4} 3 \mathrm{~g} / \mathrm{L}$, and agar $20 \mathrm{~g} / \mathrm{L}$ ) by incubating the cultures at $26{ }^{\circ} \mathrm{C}$ for 6 days. Then, these strains were kept at $4{ }^{\circ} \mathrm{C}$ in the College of Life Science, Langfang Normal University (Langfang, China).

\section{Agricultural and forestry residues}

Seven kinds of agricultural and forestry residues were used in this study. Among them, Populus beijingensis (POB), Toona sinensis (TOS), and Sophora japonica (SOJ) were obtained from Langfang city (Hebei province, China). Corncob (COC), cottonseed hull $(\mathrm{COH})$, Salix babylonica (SAB), and straw of Oryza sativa (STOS) were obtained from Chengde city (Hebei province, China). All agricultural and forestry residues were air- 
dried and ground. Particle diameter of all agricultural and forestry residues were between 20- and 60-mesh.

\section{Methods}

\section{Organism and inoculum preparation}

The microorganisms were incubated on CYM at $26{ }^{\circ} \mathrm{C}$. After 11 days, 5 inoculants as cut by use of a hole punch with diameter of $5 \mathrm{~mm}$ were placed in $250-\mathrm{mL}$ flasks containing $100 \mathrm{~mL}$ of CYM without agar. The medium containing microorganism was cultured under oscillating conditions $(120 \mathrm{rpm})$ for 7 days at $26^{\circ} \mathrm{C}$. Then, microorganisms were homogenized using a laboratory blender ( $2 \mathrm{~min}, 5000 \mathrm{rpm}$ ) and used as an inoculum.

\section{Identification of the fungus}

Mycelia of Ganoderma sp. Han 500 used for DNA extraction were grown on CYM agar medium for 9 days, and then scraped from the surfaces of CYM agar medium. The genomic DNA of the fungus was extracted by a cetyl trimethylammonium bromide rapid plant genome extraction kit (Aidlab Biotechnologies Co., Ltd., Beijing, China) according to the manufacturer's instructions with some modifications (Han et al. 2016, 2020a). The ITS regions of ribosomal DNA (rDNA) were amplified by polymerase chain reaction (PCR) using primer pairs ITS1 and ITS4. The PCR reaction schedule for ITS was referred to the method of Han et al. (2016, 2020a). The PCR products were purified and sequenced at Beijing Genomics Institute (Beijing, China). The newly generated sequence was deposited at GenBank.

Time course of laccase production by P. ostreatus CY 568 and Ganoderma sp. Han 500

Production of laccase under solid-state fermentation was performed individually in 250-mL Erlenmeyer flasks, containing dry POB $(3.0 \mathrm{~g})$ moistened with $12 \mathrm{~mL}$ deionized water. The operation method of other agricultural and forestry residues, such as TOS (3.0 g), SOJ (3.0 g), COC (3.0 g), COH (3.0 g), SAB (3.0 g), and STOS (3.0 g), was the same as the POB. All flasks were sterilized and inoculated with $3 \mathrm{~mL}$ prepared inoculum and incubated at $26{ }^{\circ} \mathrm{C}$. The flasks with fermentation agricultural or forestry residue was taken out from the incubator every $24 \mathrm{~h}$ and suspended in $100 \mathrm{~mL}$ acetate-sodium acetate buffer $(50 \mathrm{mM}, \mathrm{pH} 5.5)$. The process of extraction was performed on a rotary shaker at $10^{\circ} \mathrm{C}$ with a speed of $120 \mathrm{rpm}$ for $4 \mathrm{~h}$ (Han et al. 2020b). The contents of the flask were filtered through Whatman No. 1 filter paper, then centrifuged through a centrifuge at $4{ }^{\circ} \mathrm{C}(12,000$ $\mathrm{rpm}, 20 \mathrm{~min}$ ). The supernatant after centrifugation was used to analyze laccase activity.

\section{Laccase assay}

Laccase activity was measured using 2,2'-azinobis-[3-ethyltiazoline-6-sulfonate] (ABTS) $1 \mathrm{mM}$ as substrate in sodium acetate buffer $50 \mathrm{mM}, \mathrm{pH} 4.2$. The reaction mixture and assay method were referred to the method of Han et al. (2020b). Absorbance of the product was detected by an iMark ${ }^{\mathrm{TM}}$ Microplate Absorbance Reader (Bio-Rad, Hercules, CA, USA) and recorded at $415 \mathrm{~nm}$. One unit of enzyme activity was defined as the amount of enzyme required to oxidize $1 \mu \mathrm{mol}$ of ABTS per minute $\left(\varepsilon_{415}=3.16 \times 10^{4} \mathrm{M}^{-1} \mathrm{~cm}^{-1}\right)$.

\section{Data analysis}

All values reported are the mean values of triplicate experiments. Two-way analysis of variance followed by the Tukey post hoc test was applied to examine the effects of agricultural and forestry residues and species on laccase activities according to An et al. 
(2020a,b) using SPSS software version 22.0 (PROC GLM, IBM SPSS software version 22.0, Armonk, NY, USA). Statistical figures were generated by the software of Origin 2016 (OriginLab Corporation, Northampton, MA, USA).

\section{RESULTS AND DISCUSSION}

\section{Identification of Ganoderma sp. Han $\mathbf{5 0 0}$}

The test strain of Ganoderma sp. Han 500 was identified by molecular biology as Ganoderma lingzhi and GenBank no. MW504827.

\section{Two-way Analysis Results}

The effect of different fungi on laccase production was significant $(\mathrm{P}<0.001)$ during whole process of fermentation, except on the 8 th day $(\mathrm{P}>0.05)$. Different agricultural and forestry residues significantly affected the laccase production $(\mathrm{P}<0.001)$ throughout the fermentation stage. Moreover, the interaction of different fungi with agricultural and forestry residues on laccase production was significant $(\mathrm{P}<0.001)$ (Table $1)$.

Table 1. Two-way Analysis of Variance to Examine the Effects of Different Fungi, Agricultural and Forestry Residues, and Different Fungi $\times$ Agricultural and Forestry Residues Interactions on Laccase Production

\begin{tabular}{|c|c|c|c|}
\hline $\begin{array}{l}\text { Incubation } \\
\text { Period }(d)\end{array}$ & $\begin{array}{l}\text { Different } \\
\text { Fungi }\end{array}$ & $\begin{array}{l}\text { Agricultural and } \\
\text { Forestry Residues }\end{array}$ & $\begin{array}{c}\text { Different Fungi } \times \text { Agricultural and } \\
\text { Forestry Residues }\end{array}$ \\
\hline 1 & $2765.257^{* * *}$ & $2788.678^{\star * *}$ & $205.041^{* * *}$ \\
\hline 2 & $52.783^{* * *}$ & $38.403^{* \star *}$ & $7.049^{\star * *}$ \\
\hline 3 & $1247.785^{\star \star \star}$ & $866.749^{* * *}$ & $77.795^{\star \star \star}$ \\
\hline 4 & $1050.193^{* * *}$ & $1039.914^{* * *}$ & $81.347^{* * *}$ \\
\hline 5 & $644.688^{\star * *}$ & $1132.814^{\star * \star}$ & $56.715^{\star \star \star *}$ \\
\hline 6 & $288.239^{\star \star \star}$ & $1425.959^{\star * *}$ & $28.687^{\star \star \star}$ \\
\hline 7 & $270.973^{* * *}$ & $2025.066^{* * *}$ & $52.851^{* * *}$ \\
\hline 8 & 0.347 & $1260.403^{\star * *}$ & $111.124^{* * *}$ \\
\hline 9 & $440.071^{* * *}$ & $863.389^{* * *}$ & $88.849^{* * *}$ \\
\hline 10 & $244.813^{* * *}$ & $684.067^{* \star *}$ & $149.581^{* \star *}$ \\
\hline
\end{tabular}

\section{Production of Laccase under Different Agricultural and Forestry Residues}

Important factors affecting the laccase activity of fungi are agricultural and forestry residues belonging to complex carbon and nitrogen sources (Han et al. 2020b). Fungal growth on lignocellulosic biomass is a cheap process of enzyme production. Previous studies used less variety or quantity of lignocellulose material, such as wood chips, tree leaves, wheat bran, peanut powder or coffee shells, cultivated the fungus for growth to produce enzymes (Elisashvili et al. 2008; Fang et al. 2015). Because of the difference of laccase activity on different lignocellulosic biomass by fungi, it is important to study the laccase activity among different agricultural and forestry residues. Previous studies on 
Pleurotus ostreatus and Ganoderma lingzhi focused on laccase production induced by metals, temperature, and grown on two or three substrates (Elissetche et al. 2007; Wang et al. 2015; Postemsky et al. 2017; An et al. 2020b; Han et al. 2020b). Hence, this paper presents evaluation of laccase production by P. ostreatus CY 568 and G. lucidum Han 500 in various agricultural and forestry residues.

Overall, laccase activity from P. ostreatus CY 568 or G. lingzhi Han 500 on TOS, $\mathrm{SOJ}, \mathrm{SAB}, \mathrm{POB}, \mathrm{COC}, \mathrm{COH}$, and STOS exhibited large variation in terms of maximum or minimum laccase activity, occurrence time of maximum or minimum laccase activity, and trends in enzyme production (Figs. 1 and 2). Minimum laccase activity from P. ostreatus CY 568 occurred on day 1 on all agricultural and forestry residues, except on SAB (Fig. 1). While time of minimum laccase activity from G. lingzhi Han 500 was on day 1 from all agricultural and forestry residues (Fig. 2). In terms of time and value of maximum laccase activity, $P$. ostreatus CY 568 or G. lingzhi Han 500 secreted on different agricultural and forestry residues showed larger differences (Figs. 1 and 2). Elisashvili et al. (2008) reported that extracellular laccase activity from different $P$. ostreatus strains exhibited large variation on tree leaves, wheat straw, mandarin peels, apple, and banana peels. A previous study showed that the activity of laccase from $P$. ostreatus and $F$. velutipes strains was different on different lignocellulosic materials (An et al. 2020b). Similarly, the range of laccase enzyme production was larger on different agricultural and forestry residues in this study. Laccase activity from $P$. ostreatus CY 568 on COH was $82.88 \pm 1.98 \mathrm{U} / \mathrm{L}$ on day 1 , nearly 5.85-fold, 2.71-fold, 2.24-fold, 2.70-fold, 15.29-fold, and 12.13-fold on TOS, SOJ, SAB, POB, COC, and STOS, respectively. Laccase activity from G. lingzhi Han 500 on $\mathrm{COH}$ was $61.28 \pm 1.66 \mathrm{U} / \mathrm{L}$ on day 1 , nearly 10.00-fold, 11.52-fold, 12.71-fold, 17.41-fold, and 21.81-fold on TOS, SAB, POB, COC, and STOS, respectively. Moreover, laccase activity from $G$. lingzhi Han 500 on SOJ was undetected on day 1 . Thus, it can be seen that $\mathrm{COH}$ has a greater advantage in accelerating laccase enzyme production. Additionally, it has been previously mentioned that the presence of cottonseed hull was useful for producing laccase production quickly (An et al. 2020b).

Maximum laccase activity of $P$. ostreatus CY 568 on COH was $849.61 \pm 22.74 \mathrm{U} / \mathrm{L}$ on day 7, which was higher than that from TOS (375.33 $\pm 7.96 \mathrm{U} / \mathrm{L}$, day 8), SOJ (412.80 $\pm 6.74 \mathrm{U} / \mathrm{L}$, day 9$), \mathrm{SAB}(122.16 \pm 3.03 \mathrm{U} / \mathrm{L}$, day 4$), \mathrm{POB}\left(316.25 \pm 4.10 \mathrm{U} / \mathrm{L}, 4^{\text {th }}\right.$ day $)$, COC (345.79 $\pm 2.42 \mathrm{U} / \mathrm{L}$, day 6$)$, and STOS (367.69 $\pm 11.58 \mathrm{U} / \mathrm{L}$, day 7$)$, by 2.26 -fold, 2.06-fold, 6.95-fold, 2.69-fold, 2.46-fold, and 2.31-fold, respectively (Table 2). In terms of the value of maximum laccase activity, $\mathrm{COH}$ was beneficial to the accumulation of laccase activity for $P$. ostreatus CY 568. Based on the earliest occurrence time of maximum laccase activity (day 4), SAB $(122.16 \pm 3.03 \mathrm{U} / \mathrm{L})$ and POB $(316.25 \pm 4.10 \mathrm{U} / \mathrm{L})$ were beneficial for $P$. ostreatus CY 568. At the same time, laccase activity from $P$. ostreatus CY 568 on TOS, SOJ, COC, COH, and STOS was $213.68 \pm 12.58 \mathrm{U} / \mathrm{L}, 174.90 \pm 5.14 \mathrm{U} / \mathrm{L}, 270.14 \pm$ 24.49 U/L, 437.11 $\pm 13.68 \mathrm{U} / \mathrm{L}$, and $41.39 \pm 1.71 \mathrm{U} / \mathrm{L}$, respectively (Fig. 1). Therefore, the presence of $\mathrm{COH}$ and $\mathrm{POB}$ were helpful for accelerating the rate of laccase enzyme production of $P$. ostreatus CY 568. Maximum laccase activity of $G$. lingzhi Han 500 on $\mathrm{COH}$ was $788.73 \pm 6.12 \mathrm{U} / \mathrm{L}$ on day 8 , which was higher than that from TOS $(324.49 \pm$ $15.83 \mathrm{U} / \mathrm{L}$, day 8$)$, SOJ (259.49 $\pm 20.92 \mathrm{U} / \mathrm{L}$, day 9), SAB (36.77 $\pm 1.68 \mathrm{U} / \mathrm{L}$, day 6), POB $(228.05 \pm 10.10 \mathrm{U} / \mathrm{L}$, day 7), COC (319.07 $\pm 19.64 \mathrm{U} / \mathrm{L}$, day 7), and STOS (271.15 \pm 14.81 U/L, day 7), by 2.43-fold, 3.04-fold, 21.45-fold, 3.46-fold, 2.47-fold, and 2.91-fold, respectively (Table 2). In terms of the value of maximum laccase activity, $\mathrm{COH}$ was beneficial to the accumulation of laccase activity for G. lingzhi Han 500. Based on the earliest occurrence time of maximum laccase activity (day 6), SAB (36.77 $\pm 1.68 \mathrm{U} / \mathrm{L})$ was 
beneficial for $G$. lingzhi Han 500. At the same time, laccase activity from G. lingzhi Han 500 on TOS, SOJ, POB, COC, COH, and STOS was $247.04 \pm 5.79 \mathrm{U} / \mathrm{L}, 25.02 \pm 1.21 \mathrm{U} / \mathrm{L}$, $197.51 \pm 12.31 \mathrm{U} / \mathrm{L}, 300.38 \pm 5.36 \mathrm{U} / \mathrm{L}, 670.28 \pm 36.28 \mathrm{U} / \mathrm{L}$, and $154.61 \pm 5.36 \mathrm{U} / \mathrm{L}$, respectively (Fig. 2). Therefore, the presence of $\mathrm{COH}$ and $\mathrm{COC}$ were helpful for accelerating the rate of laccase enzyme production of G. lingzhi Han 500.

In terms of total laccase activity throughout the fermentation stage, P. ostreatus CY 568 and $G$. lingzhi Han 500 can always bring better enzyme production on $\mathrm{COH}$ due to the stable and high laccase activity. Han et al. (2020b) showed that laccase activity of tested $P$. ostreatus strains on sawdust was not always higher than that on corncob under solidstate fermentation. Similarly, maximum laccase activity from Coriolopsis trogii or Trametes versicolor on powdered walnut shell is higher than that on powdered wheat straw in submerged fermentation (Birhanli and Yeşilada 2013). Thus, these studies indicate that the lignin content is not directly related to laccase production secreted by fungi. This study showed a similar result. Han et al. (2020b) indicated that fungi grown on poplar sawdust could gain continuous and stable laccase production through solid-state fermentation. However, fungi induced by poplar sawdust could not gain stable and continuous laccase activity in submerged fermentation (An et al. 2020b). Grown on cottonseed hull moistened with deionized water, laccase production of fungi was higher than that grown on poplar wood or corncob moistened with deionized water (An et al. 2020b). In this study, continuous and stable laccase production was found on $\mathrm{COH}$ by P. ostreatus $\mathrm{CY} 568$ and G. lingzhi Han 500.

In general, $\mathrm{COH}$ was beneficial to the accumulation of laccase activity and accelerated the rate of laccase enzyme production for P. ostreatus CY 568 and G. lingzhi Han 500. The STOS was disadvantageous for P. ostreatus CY 568 and G. lingzhi Han 500 producing laccase enzyme.

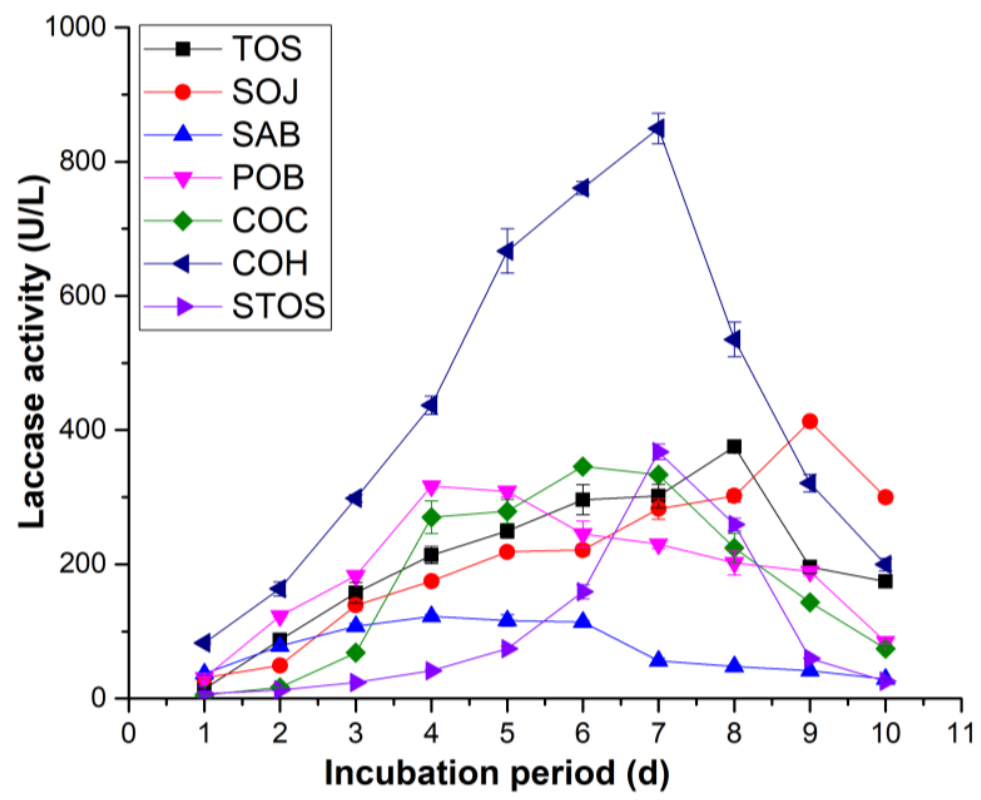

Fig. 1. Laccase production obtained from Pleurotus ostreatus CY 568 on TOS, SOJ, SAB, POB, $\mathrm{COC}, \mathrm{COH}$, and STOS by solid-state fermentation. TOS indicates Toona sinensis; SOJ indicates Sophora japonica; SAB indicates Salix babylonica; POB indicates Populus beijingensis; COC indicates corncob; $\mathrm{COH}$ indicates cottonseed hull; STOS indicates straw of Oryza sativa 


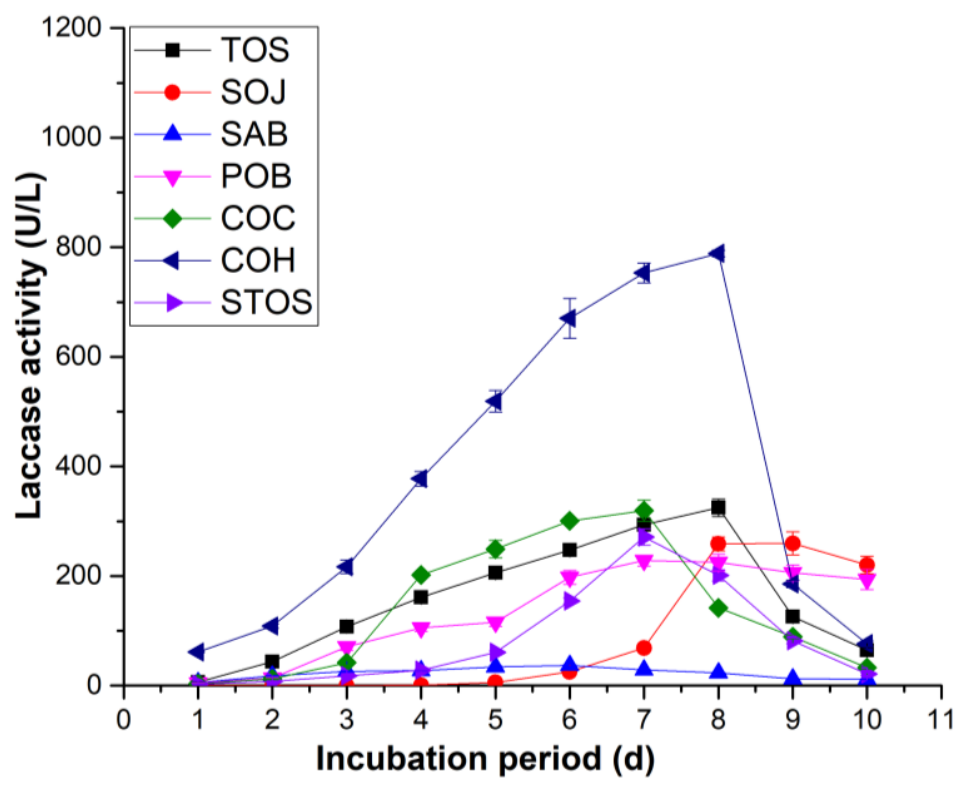

Fig. 2. Laccase production obtained from Ganoderma lingzhi Han 500 on TOS, SOJ, SAB, POB, $\mathrm{COC}, \mathrm{COH}$, and STOS by solid-state fermentation. TOS indicates Toona sinensis; SOJ indicates Sophora japonica; SAB indicates Salix babylonica; POB indicates Populus beijingensis; COC indicates corncob; $\mathrm{COH}$ indicates cottonseed hull; STOS indicates straw of Oryza sativa

Table 2. Maximum Laccase Production, Agricultural and Forestry Residues, and Time of Pleurotus ostreatus CY 568 and Ganoderma lingzhi Han 500

\begin{tabular}{|c|c|c|c|}
\hline $\begin{array}{c}\text { Maximum Laccase } \\
\text { Production (U/L) }\end{array}$ & $\begin{array}{c}\text { Agricultural and } \\
\text { Forestry Residues }\end{array}$ & Fungi & Time (day) \\
\hline $375.33 \pm 7.96$ & TOS & CY 568 & 8 \\
\hline $412.80 \pm 6.74$ & SOJ & CY 568 & 9 \\
\hline $122.16 \pm 3.03$ & SAB & CY 568 & 4 \\
\hline $316.25 \pm 4.10$ & POB & CY 568 & 4 \\
\hline $345.79 \pm 2.42$ & COC & CY 568 & 6 \\
\hline $849.61 \pm 22.74$ & COH & CY 568 & 7 \\
\hline $367.69 \pm 11.58$ & STOS & CY 568 & 7 \\
\hline $324.49 \pm 15.83$ & TOS & Han 500 & 8 \\
\hline $259.49 \pm 20.92$ & SOJ & Han 500 & 9 \\
\hline $36.77 \pm 1.68$ & SAB & Han 500 & 6 \\
\hline $228.05 \pm 10.10$ & POB & Han 500 & 7 \\
\hline $319.07 \pm 19.64$ & COC & Han 500 & 7 \\
\hline $788.73 \pm 6.12$ & COH & Han 500 & 8 \\
\hline $271.15 \pm 14.81$ & STOS & Han 500 & 7 \\
\hline \multicolumn{2}{|l|}{} & \multicolumn{2}{|l}{} \\
\hline Data are presented as mean standard deviation for triplicates and are expressed as U/L. \\
\hline
\end{tabular}

\section{Production of Laccase from Different Fungi}

Different extracellular enzyme activities of fungi can cause different decomposition and utilization of lignin, cellulose, and hemicellulose in plant cell wall (An et al. 2015). Laccase is a ligninolytic enzyme and is necessary for lignin degradation by white-rot fungi, such as Lentinus edodes, Pleurotus ostreatus, Ganoderma lucidum, Trametes versicolor, and L. crinitus (Elisashvili et al. 2008; Kuhar et al. 2015; Han et al. 2020b; Serbent et al. 2020; Xu et al. 2020). The laccase secretion capacity of different white-rot fungi was significantly different. Thus, evaluation and analysis of the capacity of different species 
secreting laccase is helpful to obtain new laccase productive species for industrial production.

Laccase activity from Pleurotus ostreatus CY 568 was detected in all agricultural and forestry residues on day 1 (Fig. 1). Laccase activity from Ganoderma lingzhi Han 500 on different agricultural and forestry residues was detected, except on SOJ (Fig. 2). Laccase activity from $P$. ostreatus CY 568 on TOS, SAB, POB, COC, COH, and STOS on day 1 was higher than that from $G$. lingzhi Han 500 by nearly 2.33 -fold, 6.95-fold, 6.38-fold, 1.54-fold, 1.35-fold, and 2.43-fold, respectively (Figs. 1, 2). Except for P. ostreatus CCMSSC 00406 strain, the laccase production of other tested $P$. ostreatus strains was more than $35 \mathrm{U} / \mathrm{L}$ on the first day, and the laccase production of Flammulina velutipes strains were less than $7 \mathrm{U} / \mathrm{L}$ on the first day (An et al. 2020b). From this view, the capacity of secreting laccase by $P$. ostreatus CY 568 and $G$. lingzhi Han 500 was superior to that by $F$. velutipes. The maximum laccase activity for $P$. ostreatus CY 568 on TOS, SOJ, SAB, POB, $\mathrm{COC}, \mathrm{COH}$, and STOS was higher than that from G. lingzhi Han 500 by nearly 1.16-fold, 1.59-fold, 3.32-fold, 1.39-fold, 1.08-fold, 1.08-fold, and 1.36-fold, respectively (Figs. 1, 2). Meanwhile, the time of maximum laccase activity for $P$. ostreatus CY 568 was earlier than that from $G$. lingzhi Han 500. In general, the capacity of P. ostreatus CY 568 secreting laccase was stronger than that of $G$. lingzhi Han 500 in this study. G. australe A464 grown on wood secreted low amount of laccase (1 to 2 IU/L) under submerged fermentation (Elissetche et al. 2007). The highest enzyme activity of G. lucidum extract cultured with ferulic acid was $49 \mathrm{U} / \mathrm{L}$ and $44 \mathrm{U} / \mathrm{L}$ on days 7 and 8, respectively (Rodrigues et al. 2019). Under the Plackett-Burman design, the highest laccase activity was observed in experiment 1 (707 U/L on day 6) and experiment 8 (785 U/L on day 7 and $607 \mathrm{U} / \mathrm{L}$ on day 8) (Rodrigues et al. 2019). In this study, maximum laccase of G. lingzhi Han 500 on TOS, SOJ, POB, COC, COH, and STOS was $324.49 \pm 15.83 \mathrm{U} / \mathrm{L}, 259.49 \pm 20.92 \mathrm{U} / \mathrm{L}, 228.05$ $\pm 10.10 \mathrm{U} / \mathrm{L}, 319.07 \pm 19.64 \mathrm{U} / \mathrm{L}, 788.73 \pm 6.12 \mathrm{U} / \mathrm{L}$, and $271.15 \pm 14.81 \mathrm{U} / \mathrm{L}$, respectively (Table 2). Thus, the laccase secretion ability of $G$. lingzhi Han 500 was good in comparison to results of previous studies.

\section{CONCLUSIONS}

1. There was a significant difference among fungi for biosynthetic potential. In general, the capacity of $P$. ostreatus CY 568 secreting laccase was stronger than that of $G$. lingzhi Han 500 in this study.

2. Different species of fungi had a preference for agricultural and forestry residues. The presence of cotton seed hull $(\mathrm{COH})$ and Populus beijingensis (POB) were useful for accelerating the rate of laccase production of $P$. ostreatus $\mathrm{CY} 568$. The presence of $\mathrm{COH}$ and corncob $(\mathrm{COC})$ were useful for accelerating the rate of laccase production of G. lingzhi Han 500.

3. Continuous and stable laccase production was found on $\mathrm{COH}$ by P. ostreatus $\mathrm{CY} 568$ and G. lingzhi Han 500.

4. The laccase secretion ability of newly isolated G. lingzhi Han 500 strain was high compared to the results about strains from genus Ganoderma in previous studies. 


\section{ACKNOWLEDGMENTS}

This research was supported by the National Natural Science Foundation of China (31900009), the Fundamental Research Funds for the Universities in Hebei Province (JQ201905), the Fundamental Research Funds for the Universities in Hebei Province (JYQ201901), the Top-notch Youth Project of Langfang City, and the Top-notch Youth Project of Colleges and Universities in Hebei Province (BJ2019007).

\section{REFERENCES CITED}

Agrawal, K., Chaturvedi, V., and Verma, P. (2018). "Fungal laccase discovered but yet undiscovered," Bioresour. Bioprocess. 5, Article Number 4. DOI: 10.1186/s40643018-0190-z

An, Q., Han, M. L., Bian, L. S., Han, Z. C., Han, N., Xiao, Y. F., and Zhang, F. B. (2020a). "Enhanced laccase activity of white rot fungi induced by different metal ions under submerged fermentation," BioResources 15(4), 8369-8383. DOI: 10.15376/biores.15.4.8369-8383

An, Q., Han, M. L., Wu, X. J., Si, J., Cui, B. K., Dai, Y. C., and Wu, B. (2016a). "Laccase production among medicinal mushrooms from the Genus Flammulina (Agaricomycetes) under different treatments in submerged fermentation," Int. J. Med. Mushrooms 18(11), 1049-1059. DOI: 10.1615/IntJMedMushrooms.v18.i11.90

An, Q., Ma, H. F., Han, M. L., Si, J., and Dai, Y. C. (2018). "Effects of different induction media as inducers on laccase activities of Pleurotus ostreatus strains in submerged fermentation," BioResources 13(1), 1143-1156. DOI:

10.15376/biores.13.1.1143-1156

An, Q., Qiao, J., Bian, L. S., Han, M. L., Yan, X. Y., Liu, Z. Z., and Xie, C. Y. (2020b). "Comparative study on laccase activity of white rot fungi under submerged fermentation with different lignocellulosic wastes," BioResources 15(4), 9166-9179. DOI: 10.15376/biores. 15.4.9166-9179

An, Q., Wu, X. J., Han, M. L., Cui, B. K., He, S. H., Dai, Y. C., and Si, J. (2016b). "Sequential solid-state and submerged cultivation of white rot fungus Pleurotus ostreatus on lignocellulosic biomass for the activity of lignocellulolytic enzymes," BioResources 11(4), 8791-8805. DOI: 10.15376/biores.11.4.8791-8805

An, Q., Wu, X. J., Wu, B., and Dai, Y. C. (2015). "Effects of carbon and nitrogen sources on lignocellulose decomposition enzyme activities in Flammulina velutipes," Mycosystema 34(4), 761-771. DOI: 10.13346/j.mycosystema.150060

Ba, S., and Kumar, V. V. (2017). "Recent developments in the use of tyrosinase and laccase in environmental applications," Crit. Rev. Biotechnol. 37(7), 819-832. DOI: 10.1080/07388551.2016.1261081

Becker, J., and Wittmann, C. (2019). "A field of dreams: Lignin valorization into chemicals, materials, fuels, and health-care products," Biotechnol. Adv. 37(6), Article ID 107360. DOI: 10.1016/j.biotechadv.2019.02.016

Bertrand, B., Martinez-Morales, F., and Trejo-Hernandez, M. R. (2017). "Upgrading laccase production and biochemical properties: Strategies and challenges," Biotechnol. Progr. 33(4), 1015-1034. DOI: 10.1002/btpr.2482

Bilal, M., Rasheed, T., Nabeel, F., Iqbal, H. M. N., and Zhao, Y. P. (2019). "Hazardous contaminants in the environment and their laccase-assisted degradation - A review," 
J. Environ. Manage. 234, 253-264. DOI: 10.1016/j.jenvman.2019.01.001

Birhanli, E., and Yeşilada, Ö. (2013). "The utilization of lignocellulosic wastes for laccase production under semisolid-state and submerged fermentation conditions," Turk. J. Biol. 37(4), 450-456. DOI: 10.3906/biy-1211-25

Castanera, R., Lopez-Varas, L., Pisabarro, A. G., and Ramirez, L. (2015). "Validation of reference genes for transcriptional analyses in Pleurotus ostreatus by using reverse transcription-quantitative PCR," Appl. Environ. Microb. 81(12), 4120-4129. DOI: 10.1128/AEM.00402-15

Christopher, L., Bissoon, S., Singh, S., Szendefy, J., and Szakacs, G. (2005). "Bleachenhancing abilities of Thermomyces lanuginosus xylanases produced by solid state fermentation," Process Biochem. 40(10), 3230-3235. DOI: 10.1016/j.procbio.2005.03.027

Elisashvili, V., Penninckx, M., Kachlishvili, E., Tsiklauri, N., Metreveli, E., Kharziani, T., and Kvesitadze, G. (2008). "Lentinus edodes and Pleurotus species lignocellulolytic enzymes activity in submerged and solid-state fermentation of lignocellulosic wastes of different composition," Bioresource Technol. 99(3), 457462. DOI: 10.1016/j.biortech.2007.01.011

Elissetche, J., Ferraz, A., Freer, J., and Rodríguez, J. (2007). "Enzymes produced by Ganoderma australe growing on wood and in submerged cultures," World J. Microbiol. Biotechnol. 23, 429-434. DOI: 10.1007/s11274-006-9243-0

Fang, Z. M., Liu, X. M., Chen, L. Y., Shen, Y., Zhang, X. C., Fang, W., Wang, X. T., Bao, X. M., and Xiao, Y. Z. (2015). "Identification of a laccase Glac15 from Ganoderma lucidum 77002 and its application in bioethanol production," Biotechnol. Biofuels 8, Article Number 54. DOI: 10.1186/s13068-015-0235-X

Fperrer-Miralles, N., Domingo-Espin, J., Corchero, J. L., Vazquez, E., and Villaverde, A. (2009). "Microbial factories for recombinant pharmaceuticals," Microb. Cell Fact. 8, Article Number 17. DOI: 10.1186/1475-2859-8-17

Filipe, D., Fernandes, H., Castro, C., Peres, H., Oliva-Teles, A., Belo, I., and Salgado, J. M. (2019). "Improved lignocellulolytic enzyme production and antioxidant extraction using solid-state fermentation of olive pomace mixed with winery waste," Biofuel. Bioprod. Bior. 14(1), 78-91. DOI: 10.1002/bbb.2073

Han, M. L., An, Q., Fu, W. X., Cheng, X., Bu, T., and Li, W. J. (2020a). "Morphological characteristics and phylogenetic analyses reveal Antrodia yunnanensis sp. nov. (Polyporales, Basidiomycota) from China," Phytotaxa 460(1), 1-11. DOI: 10.11646/phytotaxa.460.1.1

Han, M. L., An, Q., He, S. F., Zhang, X. L., Zhang, M. H., Gao, X. H., Wu, Q., and Bian, L. S. (2020b). "Solid-state fermentation on poplar sawdust and corncob wastes for lignocellulolytic enzymes by different Pleurotus ostreatus strains," BioResources 15(3), 4982-4995. DOI: 10.15376/biores.15.3.4982-4995

Han, M. L., An, Q., Wu, X. J., Zheng, F., and Si, J. (2017). "Effects of different lignocellulose as inducers on laccase activities of Pleurotus ostreatus in submerged fermentation," Mycosystema 36(3), 349-357. DOI: 10.13346/j.mycosystema. 160055

Han, M. L., Chen, Y. Y., Shen, L. L., Song, J., Vlasák, J., Dai, Y. C., and Cui, B. K. (2016). "Taxonomy and phylogeny of the brown-rot fungi: Fomitopsis and its related genera," Fungal Diversity 80(1), 343-373. DOI: 10.1007/s13225-016-0364-y

Huang, L., Sun, N., Ban, L., Wang, Y., and Yang, H. P. (2019). “Ability of different edible fungi to degrade crop straw," AMB Expr. 9, Article Number 4. DOI: $10.1186 / \mathrm{s} 13568-018-0731-\mathrm{z}$ 
Janusz, G., Czuryło, A., Frąc, M., Rola, B., Sulej, J., Pawlik, A., Siwulski, M., and Rogalski, J. (2015). "Laccase production and metabolic diversity among Flammulina velutipes strains,” World J. Microb. Biot. 31(1), 121-133. DOI: 10.1007/s11274-0141769-y

Ko, E. M., Leem, Y. E., and Choi, H. T. (2001). "Purification and characterization of laccase isozymes from the white-rot basidiomycete Ganoderma lucidum," Appl. Microbiol. Biot. 57(1-2), 98-102. DOI: 10.1007/s002530100727

Kuhar, F., Castiglia, V., and Levin, L. (2015). "Enhancement of laccase production and malachite green decolorization by co-culturing Ganoderma lucidum and Trametes versicolor in solid-state fermentation," Int. Biodeter. Biodegr. 104, 238-243. DOI: 10.1016/j.ibiod.2015.06.017

Kuhar, F., and Papinutti, L. (2014). "Optimization of laccase production by two strains of Ganoderma lucidum using phenolic and metallic inducers," Rev. Argent. Microbiol. 46(2), 144-149. DOI: 10.1016/S0325-7541(14)70063-X

Lamia, M. H., Farid, Z., Sonia, M. A., Sevastianos, R., Samia, A., Véronique, D., and Mouloud, K. (2017). "Selective isolation and screening of actinobacteria strains producing lignocellulolytic enzymes using olive pomace as substrate," Iranian J. Biotech. 15(1), 74-77. DOI: 10.15171/ijb.1278

Lira-Perez, J., Rodriguez-Vazquez, R., and Chan-Cupul, W. (2020). "Effect of fungal cocultures on ligninolytic enzyme activities, $\mathrm{H}_{2} \mathrm{O}_{2}$ production, and orange $\mathrm{G}$ discoloration," Prep. Biochem. Biotech. 50(6), 607-618. DOI: 10.1080/10826068.2020.1721534

Mate, D. M., and Alcalde, M. (2017). "Laccase: A multi-purpose biocatalyst at the forefront of biotechnology," Microb. Biotechnol. 10(6), 1457-1467. DOI: $10.1111 / 1751-7915.12422$

Metreveli, E., Kachlishvili, E., Singer, S. W., and Elisashvili, V. (2017). "Alteration of white-rot basidiomycetes cellulase and xylanase activities in the submerged cocultivation and optimization of enzyme production by Irpex lacteus and Schizophyllum commune," Bioresource Technol. 241, 652-660. DOI: 10.1016/j.biortech.2017.05.148

Osma, J. F., Toca-Herrera, J. L., and Rodriguez-Couto, S. (2011). "Cost analysis in laccase production,” J. Environ. Manage. 92(11), 2907-2912. DOI: 10.1016/j.jenvman.2011.06.052

Palazzolo, M. A., Postemsky, P. D., and Kurina-Sanz, M. (2019). "From agro-waste to tool: Biotechnological characterization and application of Ganoderma lucidum E47 laccase in dye decolorization," 3 Biotech 9(6), Article Number 213. DOI: 10.1007/s13205-019-1744-2

Postemsky, P. D., Bidegain, M. A., Gonzalez-Matute, R., Figlas, N. D., and Cubitto, M. A. (2017). "Pilot-scale bioconversion of rice and sunflower agro-residues into medicinal mushrooms and laccase enzymes through solid-state fermentation with Ganoderma lucidum," Bioresource Technol. 231, 85-93. DOI: 10.1016/j.biortech.2017.01.064

Rajavat, A. S., Rai, S., Pandiyan, K., Kushwaha, P., Choudhary, P., Kumar, M., Chakdar, H., Singh, A., Karthikeyan, N., Bagul, S. Y., et al. (2020). "Sustainable use of the spent mushroom substrate of Pleurotus florida for production of lignocellulolytic enzymes," J. Basic Microb. 60(2), 173-184. DOI: 10.1002/jobm.201900382

Rodrigues, E. M., Karp, S. G., Malucelli, L. C., Helm, C. V., and Alvarez, T. M. (2019). "Evaluation of laccase production by Ganoderma lucidum in submerged and solid- 
state fermentation using different inducers," J. Basic Microb. 59(8), 784-791. DOI: 10.1002/jobm.201900084

Serbent, M. P., Guimaraes, D. K. S., Drechsler-Santos, E. R., Helm, C. V., Giongo, A., and Tavares, L. B. B. (2020). "Growth, enzymatic production and morphology of the white-rot fungi Lentinus crinitus (L.) Fr. upon 2,4-D herbicide exposition,” Int. J. Environ. Sci. Technol. (Tehran) 17(5), 2995-3012. DOI: 10.1007/s13762-020-02693-1

Sharma, A., Jain, K. K., Srivastava, A., Shrivastava, B., Thakur, V. V., Jain, R. K., and Kuhad, R. C. (2019). "Potential of in situ SSF laccase produced from Ganoderma lucidum RCK 2011 in biobleaching of paper pulp," Bioproc. Biosyst. Eng. 42(3), 367377. DOI: 10.1007/s00449-018-2041-X

Shrestha, P., Joshi, B., Joshi, J., Malla, R., and Sreerama, L. (2016). "Isolation and physicochemical characterization of laccase from Ganoderma lucidum-CDBT1 isolated from its native habitat in Nepal," Biomed Res. Int. 2016, Article ID 3238909. DOI: $10.1155 / 2016 / 3238909$

Singhania, R. R., Patel, A. K., Soccol, C. R., and Pandey, A. (2009). "Recent advances in solid-state fermentation," Biochem. Eng. J. 44(1), 13-18. DOI: 10.1016/j.bej.2008.10.019

Singh, G., and Arya, S. K. (2019). "Utility of laccase in pulp and paper industry: A progressive step towards the green technology," Int. J. Biol. Macromol. 134, 10701084. DOI: 10.1016/j.ijbiomac.2019.05.168

Singh, J., Kumar, P., Saharan, V., and Kapoor, R. K. (2019). "Simultaneous laccase production and transformation of bisphenol-A and triclosan using Trametes versicolor," 3 Biotech 9(4), Article Number 129. DOI: 10.1007/s13205-019-1648-1

Sitarz, A. K., Mikkelsen, J. D., Højrup, P., and Meyer A. S. (2013). "Identification of a laccase from Ganoderma lucidum CBS 229.93 having potential for enhancing cellulase catalyzed lignocellulose degradation," Enzyme Microb. Technol. 53(6-7), 378-385. DOI: 10.1016/j.enzmictec.2013.08.003

Soccol, C. R., Costa, E. S. F. d., Letti, L. A. J., Karp, S. G., Woiciechowski, A. L., and Vandenberghe, L. P. d. S. (2017). "Recent developments and innovations in solid state fermentation," Biotechnol. Res. Innov. 1(1), 52-71. DOI: 10.1016/j.biori.2017.01.002

Steudler, S., and Bley, T. (2015). "Better one-eyed than blind - Challenges and opportunities of biomass measurement during solid-state fermentation of basidiomycetes," Adv. Biochem. Eng. Biotechnol. 149, 223-252. DOI: 10.1007/10_2014_300

Su, J., Fu, J. J., Wang, Q., Silva, C., and Cavaco-Paulo, A. (2018). “Laccase: A green catalyst for the biosynthesis of poly-phenols," Crit. Rev. Biotechnol. 38(2), 294-307. DOI: $10.1080 / 07388551.2017 .1354353$

Szendefy, J., Szakacs, G., and Christopher, L. (2006). "Potential of solid-state fermentation enzymes of Aspergillus oryzae in biobleaching of paper pulp," Enzyme Microb. Technol. 39(6), 1354-1360. DOI: 10.1016/j.enzmictec.2006.06.016

Unuofin, J. O., Okoh, A. I., and Nwodo, U. U. (2019). "Aptitude of oxidative enzymes for treatment of wastewater pollutants: A laccase perspective," Molecules 24(11), Article Number 2064. DOI: 10.3390/molecules24112064

Wang, Q., Ding, L., and Zhu, C. W. (2018). "Characterization of laccase from a novel isolated white-rot fungi Trametes sp. MA-X01 and its potential application in dye decolorization," Biotechnol. Biotec. Eq. 32(6), 1477-1485. DOI:

10.1080/13102818.2018.1517028 
Wang, H. L., Li, P., Yang, Y. H., and Liu, Y. F. (2015). “Overproduction of laccase from a newly isolated Ganoderma lucidum using the municipal food waste as main carbon and nitrogen supplement," Bioproc. Biosyst. Eng. 38(5), 957-966. DOI: 10.1007/s00449-014-1341-z

Xu, S., Wang, F., Fu, Y. P., Li, D., Sun, X. Z., Li, C. T., Song, B., and Li, Y. (2020). "Effects of mixed agro-residues (corn crop waste) on lignin-degrading enzyme activities, growth, and quality of Lentinula edodes," RSC Adv. 10(17), 9798-9807. DOI: $10.1039 / \mathrm{c} 9 \mathrm{ra} 10405 \mathrm{~d}$

Yang, J., Li, W. J., Ng, T. B., Deng, X. Z., Lin, J., and Ye, X. Y. (2017). “Laccases: Production, expression regulation, and applications in pharmaceutical biodegradation," Front. Microbiol. 8, Article Number 832. DOI: 10.3389/fmicb.2017.00832

You, L. F., Liu, Z. M., Lin, J. F., Guo, L. Q., Huang, X. L., and Yang, H. X. (2014). "Molecular cloning of a laccase gene from Ganoderma lucidum and heterologous expression in Pichia pastoris," J. Basic Microb. 54, S134-S141. DOI: 10.1002/jobm.201200808

Zerva, A., Simic, S., Topakas, E., and Nikodinovic-Runic, J. (2019). "Applications of microbial laccases: Patent review of the past decade (2009-2019)," Catalysts 9, Article Number 12. DOI: 10.3390/catal9121023

Article submitted: January 23, 2021; Peer review completed: April 17, 2021; Revised version received and accepted: May 28, 2021; Published: June 4, 2021.

DOI: $10.15376 /$ biores.16.3.5287-5300 